\title{
The Relation between Tokens and Blockchain Networks: The Case of Medical Tourism in the Republic of Moldova
}

Marc Pilkington

University of Burgundy Franche-Comté, France

Correspondence: Marc.Pilkington@u-bourgogne.fr

Received: 15 October 2020 Accepted: 10 November 2020 Published: 30 November 2020

\begin{abstract}
The relation between blockchain tokens and the underlying networks as a determinant of success of use cases in the blockchain space is an insuffciently explored issue in the literature. In the first part, we examine the token/network relation strength of various DLT tourism projects. We find that non-monetary and non-financial use cases perform better than cryptocurrencies, and online coverage is a poor predictor of success. Secondly, we provide preliminary empirical support to blockchain for tourism in the Republic of Moldova, a country, which is interesting insofar as it features nascent medical tourism and blockchain industries with great potential. Thirdly, we further our analysis and investigate the intersection between medical tourism and blockchain technology. We provide evidence that untapped socio-economic potential exists in these sectors.
\end{abstract}

Keywords: blockchain, Republic of Moldova, token, medical tourism, bealth care, use cases

JEL Classifications: I11, L83, O14, P27, Z30

\section{Introduction}

Tourism is undergoing a wide-ranging process of transformation set in motion by digitalisation [1]. To meet emerging customer needs and build innovative platforms [2], the tourism industry combines money, technology and knowledge. Of particular interest is distributed ledger technology (hereafter DLT), a powerful driver of a technological revolution that creates new opportunities for tourism companies [3].

A blockchain is a distributed, shared, encrypted-database that serves as an irreversible and incorruptible public repository of information. It enables unrelated people to reach consensus on the occurrence of a particular transaction or event without the need for a controlling authority [4].

First, we review token-based versus non-token-based growth drivers in the tourism industry and define a project's token/network relation strength accordingly. We are critical of tokens designed for pure monetary use cases. We analyse a tourism ecosystem-enhancing project on the island of Agistri in 2015, which has not passed the 'smell test' [5] since.

We then look at a failed initial coin offering (ICO) in the loyalty industry that bears resemblance to complementary currency systems. Some use cases are dressed in the clothes of mediatised success stories, but hype is seldom a good predictor of success. We therefore investigate more promising non-native token-based use cases with weaker network/token relation strength.

Secondly, we analyse the results of a small questionnaire-based survey in the Republic of Moldova (hereafter RM), a small and under-researched country where both tourism and blockchain sectors are embryonic. In spite of the small sample, our empirical survey serves as a stepping stone for Part 3.

Finally, we investigate the intersection between DLT and medical tourism, focusing on RM.

Table 1: Analysis of all cited DLT companies (external backing in the endnotes)

\begin{tabular}{|c|c|c|}
\hline $\begin{array}{c}\text { Blockchain } \\
\text { project }\end{array}$ & $\begin{array}{c}\text { Success/Failure indicator } r^{\mathrm{i}} \\
\text { (green, orange, or red) }\end{array}$ & Relation Strength \\
\hline Destinia & $\begin{array}{l}\text { Customer complaints } \\
(\text { BTC acceptability })^{i i}\end{array}$ & Medium \\
\hline CheapAir & $\begin{array}{l}\$ 5,000,000+\text { processed in } \\
\text { BTCpayments since } 2013 \text { iii }\end{array}$ & Medium \\
\hline AirBaltic & $\begin{array}{l}\text { Growth in 2017, number of } \\
\text { customers using BTC in } \\
2018 / 2019 \text { was stableiv. }\end{array}$ & Medium \\
\hline Far Eastern Air & Has ceased operations $^{v}$ & Medium \\
\hline aBitSky & Good reviews & Medium \\
\hline Norwegian Air & Popular; low-cost policy vii & Medium \\
\hline Marco Coino & $\begin{array}{l}1958 \text { brick-and-mortar } \\
\text { merchants listedviii }\end{array}$ & Medium \\
\hline
\end{tabular}




\begin{tabular}{|c|c|c|}
\hline RippleNet & $\begin{array}{c}\text { RippleNet Usage Surges } \\
300 \% \text { In 2020 Q1 }\end{array}$ & Medium \\
\hline Nautiluscoin & Dead coin since Nov. 2017 & Symbiotic \\
\hline DT Token & Dead coin since 2017 & Symbiotic \\
\hline Chain of Points & Failed ICO on 31/03/2017 & Medium to high \\
\hline Fizzy (Axa) & $\begin{array}{c}\text { Experienced ended in } \\
\text { November 2019x }\end{array}$ & Loose \\
\hline Buuyers & $\begin{array}{c}\text { Buuyers was removed from } \\
\text { the Trade and Companies } \\
\text { Register on 05/20/2019xi }\end{array}$ & Loose \\
\hline $\begin{array}{c}\text { Microsoft + } \\
\text { Webjet }\end{array}$ & $\begin{array}{c}\text { Unveils Rezchain at World } \\
\text { Travel Market (11/2019) } \text { xii }\end{array}$ & Loose \\
\hline Amadeus IT & $\begin{array}{c}\text { «Blockchain is overhyped» } \\
\text { Rashesh Jethi, Head of } \\
\text { innovation for Airlines xiii }\end{array}$ & Loose \\
\hline Sihatech & $\begin{array}{c}\text { Sihatech listed amongst the } \\
\text { world's top 10 startups }{ }^{\text {xiv }}\end{array}$ & Loose \\
\hline
\end{tabular}

\section{Four types of blockchain/token relations}

Scholarly controversy exists as to whether or not 'the coin is an integral part of the network's incentive mechanism to maintain its security', and if 'the two have an existential symbiotic relationship' [6]. We offer to shed light on this debate in this study. In Proof-of-Work systems, miners contribute to the network, and are rewarded with tokens if they first solve a mathematical puzzle, in order to validate a transaction' [7]. Yet, not all blockchains are token-based, and not all tokens perform a monetary function [8]. We propose a classification of use cases depending on the strength of the relation between the token and the network: (1) symbiotic, (2) medium-to-high, (3) loose-to-medium and (4) weak. Table 1 features all surveyed DLT companies in this article.

Our clustering method draws on a simplified (and noncomputed) Jenks optimization method [9] in order to classify blockchain features by creating homogenous classes, and using natural breaks in data valuesxv. We provide a novel measurement space in order to quantify the extent to which use cases deploy a native token (a currency application). Our statistical arrangement is structured around two discontinuous discretionary variables (token/network relation strength and success indicator). Hence the value $r=1$ (i.e. monetary use case) corresponds to a symbiotic relation featuring a native token. By no means does this maximal value imply that the underlying use case is flawless. Frequent flyer miles are a form of near money or quasi money [10]. Blockchain-powered loyalty points are native tokens redeemable in the form of discounts and rewards. Yet one cannot pay directly for the afferent services therewith, hence the value $\mathrm{r}=0.8$. Some use cases enable (monetary) payment in BTC (or other cryptocurrencies), but the latter being non-native tokens, these use cases are not symbiotic in the sense defined above; hence, the value $r=0.5$. Finally, smart contracts (e.g. automated compensation for insurance claims), certification, or record keeping use cases may involve a payment authorization. However, tokens perform a peripheral and nonmonetary function, hence our chosen value $\mathrm{r}=0.2$. It may be argued that the statistical data featured in Table 1 and Figure 7 is not directly observable, and therefore difficult to interpret. We disagree with this claim insofar as the numerical assessment of the success/failure of the projects, and the token/network relation, was based on all public information available (press releases, articles and company reports; see fn from ii to xiv in Table 1) and the expertise of the author in the field of DLT.

\section{Symbiotic relation}

In the midst of a political crisis in June 2015 following a no-vote to a referendum with prolonged fears of a 'Grexit' [11], capital controls and defiance towards the banking sector, the Greek island of Agistri tested a cryptocurrency called Nautiluscoin [12], in order to kick-start the local tourism industry. In spite of the media coverage, the project was short-lived with allegations of scams with ramifications in RM [13]. DLT entrepreneur Antonoupoulos has voiced criticism at Nautiluscoin, pointing to its absurdity in a tweet questioning the alleged superiority of a cryptocurrency solution to the Greek crisis over a mere cashbased one (Figure 1). While debunking the Nautiluscoin scam, Miller [14] criticizes the potential of any monetary cryptoinstrument to boost tourism on the island of Agistri:

Kelly has struck a deal with the Mayor of Agistri to use the small island as a 'pilot program' [...] how will he convince merchants to accept Nautiluscoin? Kelly cites tourism as the vector for promoting Nautiluscoin. I don't understand how an altcoin will promote tourism. My research indicates the island is already a tourist destination, so let's assume that's true. I have to imagine in times of crisis, merchants want what tourists already have: cold, hard cash.

Confirming the predictions of Antonopoulos [15] and Miller [14], Nautiluscoin crashed in late 2017 (Figure 2). DT Token [16], an altcoin issued by a developer affiliated to a Nautiluscoin stakeholder, promising massive discounts and loyalty rewards in the tourism sector, officially became a dead coin the same year (Figure 3). Both displayed a symbiotic relationship: $r=1$.
AndreasmAntonopoulos

Greeks already have cash in hand, bitcoin is unnecessary. If they don't, then bitcoin is unattainable. It's a bank liquidity crisis.

\section{7 व日9}

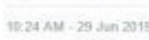

Figure 1: Tweet by Andreas Antonopoulos on 29 June 2015 Source: Twitter

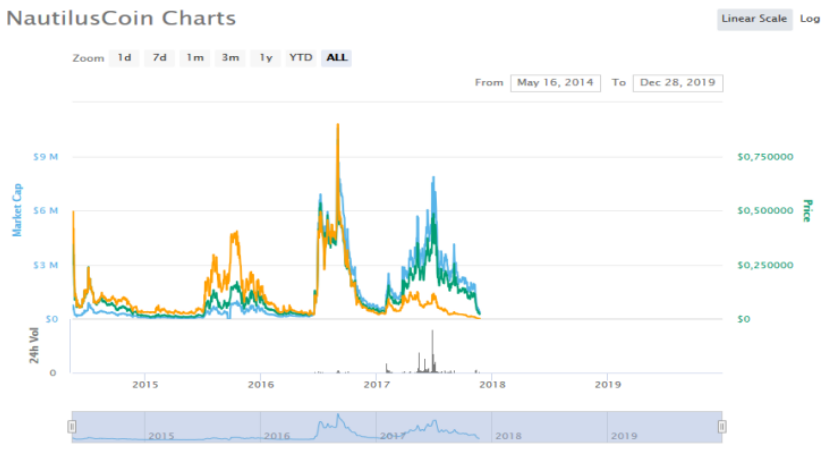

Figure 2: Evolution of the Nautiluscoin price (2015-18) Source: https://coinmarketcap.cm/ko/currencies/nautiluscoin/ 


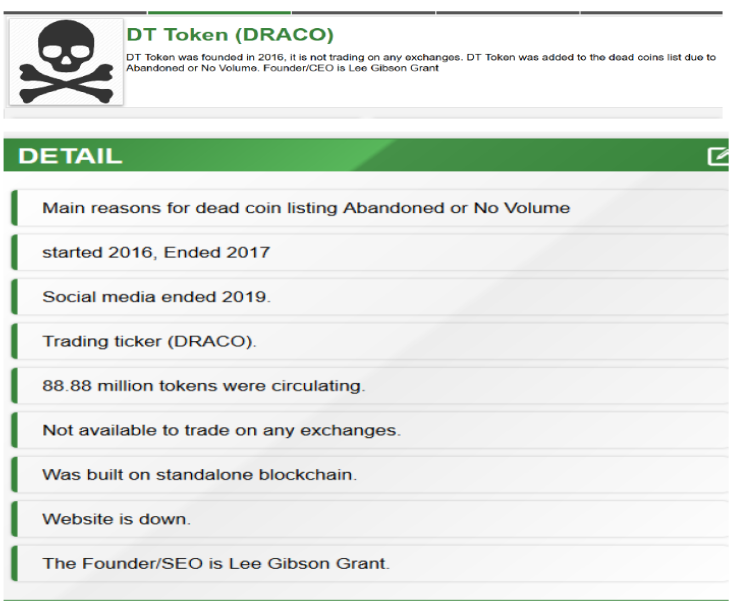

Figure 3: The death of DT Token

Source: https://www.coinopsy.com/dead-coins/dt-token/

\section{Medium-to-bigh relations (loyalty schemes)}

Hereafter, a medium-to-high relationship $r=0.8$ is posited for loyalty and rewards. DLT has a transformative potential for improving loyalty programs [17]. Considering that most accumulated points in loyalty programs, always very popular in the tourism sector, worth $\$ 50$ billion [18], are never redeemed, the startup Chain of Points had sought to use its own token to incentivize participation in loyalty schemes [19]. Tokenization experiments of loyalty and rewards programs mirror complementary currency systems:

a specific unit (or system) of account that complements the official currency and has been developed by a group of agents (individuals, economic and social structures, local authorities or banks) that has formed a local network with a view to accounting for and regulating exchanges of goods and services [20].

These ambitious crowdsale announcements eventually proved delusional [21]. Figure 4 shows that the ICO has failed, while www.chainofpoints.com was inactive at the time of writing.

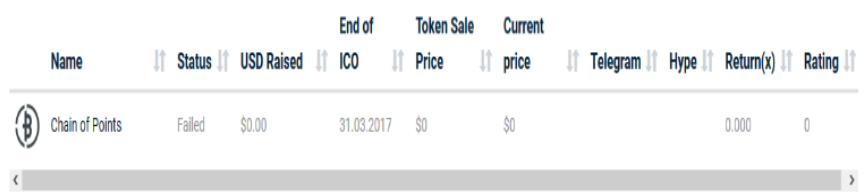

Figure 4: The failure of the Chain of Points ICO Source: https://www.icodata.io/ICO

In Table 2, we document the intensive media coverage of both failed projects received over short periods of time (with $\mathrm{r}=1$ and $r=0.8$ ). In light of these disappointing results, we claim that against the odds, the most fruitful DLT use cases in the tourism sector lie outside the financial and monetary sphere, and display week or medium relation strength.

\section{Loose-to-medium relation}

For the following non-native token-based and financial use cases, $\mathrm{r}=0.5$ (Table 2). In Thailand, tourists are wary of credit card fraud and seek merchants accepting Bitcoin [22]. Destinia, in 2013-14, began to list its prices in Bitcoin. Online booking site CheapAir, Latvian national airline AirBaltic, Taiwan's Far Eastern Air [23], aBitSky, Norwegian Air all accept payment in Bitcoin. In Southeast Asia, there is increasing acceptance of Bitcoin Cash [24]. Marco Coino is an application that helps locate brick and mortar stores accepting Bitcoin Cash (Figure 5). With Bitcoin and Bitcoin Cash being already established cryptocurrencies, these use cases are devoid of native blockchain tokens and do not qualify for symbiotic token/network relation. Rather, we opted for medium relation strength (Table 1).

A resilient banking system provides reassurance to tourists, and enhances the competitiveness of tourism destinations. DLT financial applications [25] pertain to compliance costs, clearing and settlement, Know-Your-Client (KYC) and AntiMoney-Laundering (AML), and help strengthen banking operations.

Table 2: Online coverage for our two (near) monetary use cases

\begin{tabular}{|c|c|}
\hline $\begin{array}{l}\text { Digital currency project for Agistri } \\
\text { island: media sources over a period of } \\
\text { three months. }\end{array}$ & $\begin{array}{l}\text { Initial Coin Offering of } \\
\frac{\text { Chain of Points: }}{\text { period of six weeks }}\end{array}$ \\
\hline $\begin{array}{l}\text { A bitcoin-like solution for Greece CNBC Article } \\
\text { 8th of May } 2015 \text { by Brian Kelly } \\
\text { Drachmae: a Bitcoin-like Solution for Greece's } \\
\text { Troubled Economy Bitcoin Magazine 14th May } \\
2015 \text { by Giulio Prisco } \\
\text { Drachmae: Could bitcoin-inspired currency be } \\
\text { the answer to Greece's economic woes? } \\
\text { International Business Times Article 15th of May } \\
2015 \text { by Anthony Cuthbertson } \\
\text { Could a digi-drachma avert a Grexit? Reuters } \\
\text { BY JEMIMA KELLY June 5th 2015 } \\
\text { Electronic currency can rescue Greek } \\
\text { economy, The Argus by Finn Scott-Delany } \\
\text { Tuesday 9 June 2015 } \\
\text { Worried about Greece holidays? Should you } \\
\text { go, where to stay, safety tips - facts to know, } \\
\text { Sunday Express Newspaper 3rd July 2015 by } \\
\text { FELICITY } \\
\text { Greek Economic Crisis: Is A 'Parallel' } \\
\text { Currency The Answer?, Forbes 5th of July 2015 } \\
\text { Roger Aitken } \\
\text { Greek island agrees to test digital currency, } \\
\text { CNBC 8th of July 2015 by Brian Kelly } \\
\text { Tourists nearly absent for Greek island's peak } \\
\text { season, Greek islands, normally packed this time } \\
\text { of year, are struggling to get by. CNN's Phil Black } \\
\text { reports. 11th July 2015 } \\
\text { Criptomonedas y Blockchain formarán parte } \\
\text { del show televisivo 'Athena' en la isla griega de } \\
\text { Agistri, criptonoticias by Jaime Sandoval 24th } \\
\text { August 2015 } \\
\text { Digital currency ecosystem tested on island, } \\
\text { TechCityNews 23rd November 2015 Nia Williams } \\
\text { Drachmae Preview and Interviews Agistri, } \\
\text { Greece ecosystem tested in Agistri, Ikon Media } \\
\text { 5th December 2015 } \\
\text { How Bitcoin Disrupts Telecommunications, } \\
\text { 28th February 2016, by Kokkinos Marinos, } \\
\text { Cointelegraph } \\
\text { Drachmae Project plans blockchain based } \\
\text { travel club Token Crowdsale, 2nd May 2016, } \\
\text { Hans Lombardo, AllCoinsNews } \\
\text { Chainreactor Beta-Testing Permissioned } \\
\text { Blockchain with DT-Chain } 16 \text { th May 2016, } \\
\text { Hans Lombardo, Blockchain Finance } \\
\text { Is A Blockchain Solution for 'Brexit' Voting \& } \\
\text { Transparency The Answer? Forbes 5th of July } \\
\text { 2015 Roger Aitken }\end{array}$ & $\begin{array}{l}\text { Chain of Points Launches } \\
\text { Crowdsale to Help Small } \\
\text { Businesses with Loyalty, Finance } \\
\text { Magnates, Avi Mizrahi, 18 January, } \\
2017 \\
\text { Can Blockchain Help Loyalty } \\
\text { Programs? Bitcoin Magazine 27th } \\
\text { February } 2017 \text { by Michael Scott } \\
\text { IPayYou CEO Kavner Joins } \\
\text { Blockchain Loyalty Startup } \\
\text { Chain Of Points Coin Telegraph } \\
\text { 27th February } 2017 \text { by William } \\
\text { Suberg }\end{array}$ \\
\hline
\end{tabular}


Comment: in spite of substantial media coverage and hype, both projects have failed to live up to expectations.

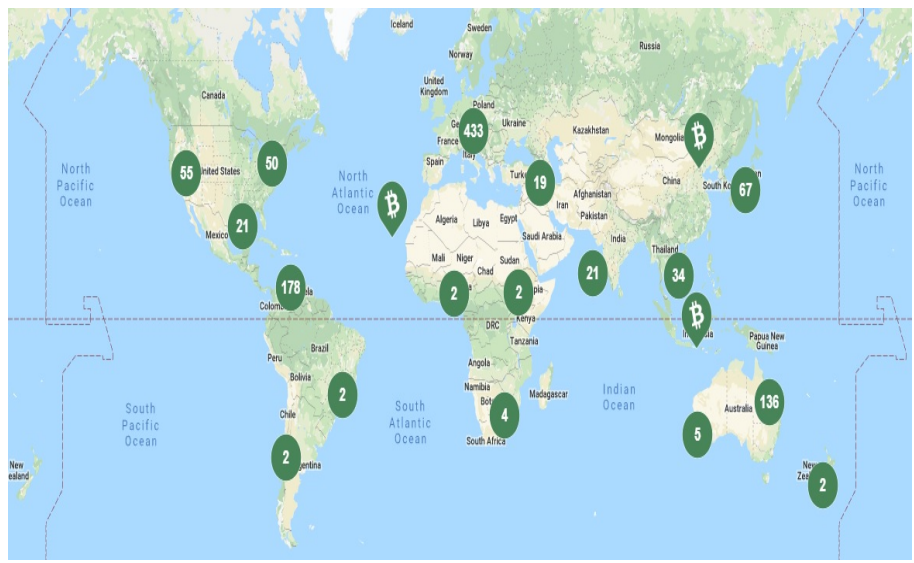

Figure 5: Bitcoin Cash Map Source: https://map.bitcoin.com/

RippleNet is a global network of more than 300 financial institutions worldwide enabling faster, lower-cost payments. Recently, Ripple Inc. announced an upgrade of RippleNet, and the launch of 'Easy App', a QR code-based application enabling tourists in Thailand to pay for goods and tourism services without needing to change currencies beforehand [26]. Although it uses a native cryptocurrency called XRP, RippleNet is best seen as a challenger of the SWIFT network, relying on established banking institutions and fiat currencies to sustain its cross-border operations $(r=0.5)$.

\section{Weak relation}

For smart contracts, review certification, online booking and e-healthcare, $r=0.2$. Smart contracts are blockchain-powered programmes, for deciding whether an operation should be permitted. They can send an acknowledgement or (nonmonetary) token access mechanism to the physical asset, or a user e-wallet, to open a rental car or hotel room [27]. Fizzy [28] was a web and mobile insurance cover experiment for flight delays that ended in November 2019 [29]. The compensation of a loss is no longer based on expert assessments of customer claims, but on data stored on the blockchain. Axa ended the experiment in November 2019.

Travel sites often aggregate reviews and ratings about tourism service providers [30]. These online user-generated reviews tend to dramatically reshape the tourism industry [31]; controversy surrounding verified opinions, distorted rankings, and satisfaction rate authenticity has not ended [32]. Buuyers (Figure 6) set out to offer a customer review management tool, in order to monitor the online reputation. It offered professionals an innovative and collaborative label that would ensure the most transparent customer relationships. By certifying reviews before registering them on the blockchain, transparency and credibility could have been increased [33].

Microsoft and Webjet have designed a blockchain proof-ofconcept travel solution, facilitating booking data processing [34]. The new blockchain called Rezchain powered by
Microsoft Azure, consisting in a smart contract solution and data reconciliation service [35], was successfully launched by Webjet [36]. It helps streamline processes, and reduces costs across the industry with substantial reduction in losses associated with transaction disputes. The travel industry has suffered massively from the 2020 coronavirus pandemic; the Webjet share price is nonetheless showing signs of resilience.

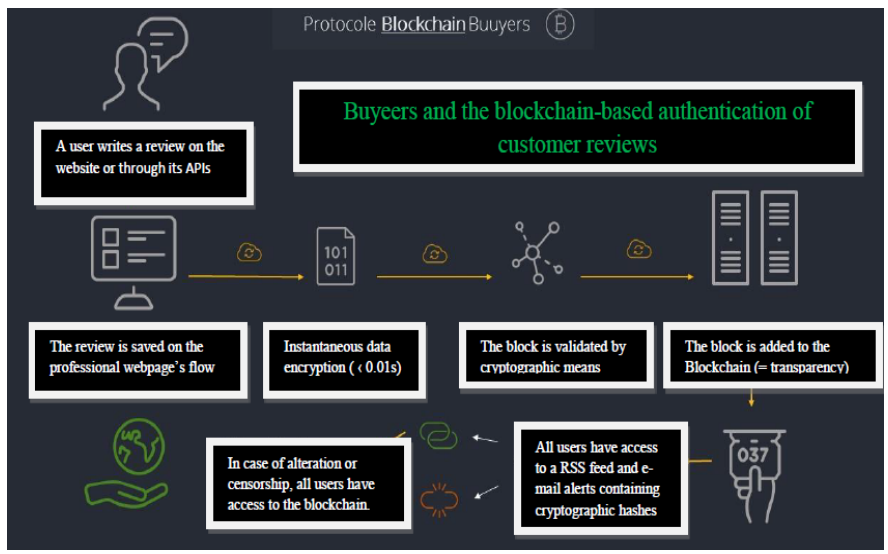

Figure 6 Authentication of customer reviews Source: Buuyers

Authenticity in tourism [37] [38] comes under many forms. Tourists in search of authenticity in a restaurant can keep an eye on the food supply chain [39] [40].

Travelers are required to show their ID at multiple stages of their journey from booking to boarding to checking in at the hotel. DLT increases security while simplifying traveller identification [41].

Gamification is the process of layering game-like features onto a platform. Combined with DLT and mobile services, it enables early-stage innovation and engagement in the creative process [42]. Destination marketing organisations and tourists benefit from gamified mobile experiences [43].

In case of emergency, access to a permissioned blockchain helps detect a competent expert, who has access to the healthcare data remotely in case of a rare condition. Patients can store encrypted vital information and instruct who has access to the private key and the medical information. The ledger stores medical procedures and advanced directives, such as not-to-resuscitate orders [44]. Sihatech is funded by Saudi Aramco (worth \$2 trillion) through the Aramco Entrepreneurship Ventures Fund. Sihatech has built the largest database of private doctors in Saudi Arabia and has launched an elective medical procedure financing module called Jamalek. Sihatech is listed amongst the world's top 10 start-ups [45].

Interpretation: Successful projects cited in this study display weak or loose network/token relation strength. Furthermore, there is no correlation between online coverage measured by Google search results, and the two discretionary variables (success/failure and token/network relation strength). 

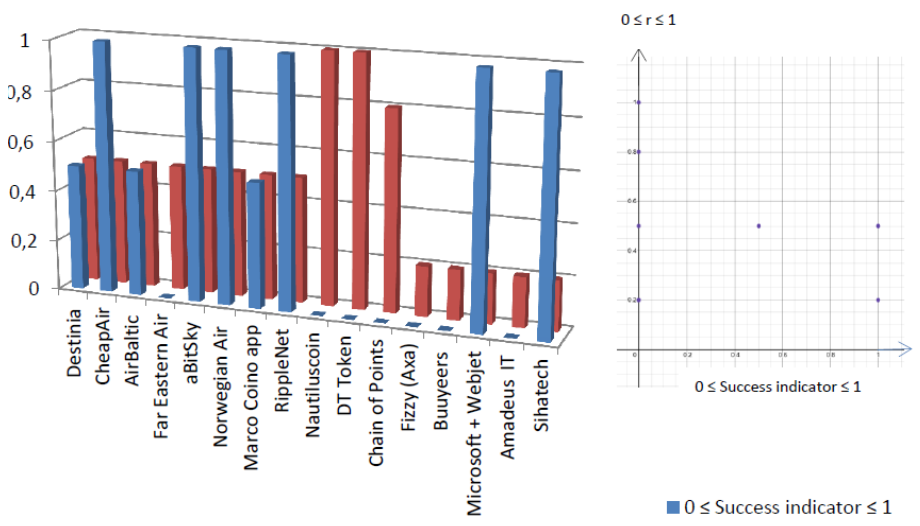

Correlation coefficient: $r s=-0.1776$

$0 \leq$ Success indicator $\leq 1$ Relationship strength: $\mathrm{r}$

p-value: 0.51

\{HO: no correlation between $\llbracket$ and $\llbracket$ is not rejected

Figure 7: 3D representation of all use cases

\section{Questionnaire-based survey on DLT in Moldova}

We conducted a small online survey on the potential of DLT for tourism in RM for a segment of the tourism industry, namely medical tourism. We collected the answers to ten questions by (only) four respondents, who all hold a senior management function bearing an either direct or indirect relationship to the Moldovan tourism industryxvi. Of course, the small size of the sample prevents us from inferring any statistical significance therefrom. Yet, given a combination of limiting factors such as country size, the embryonic tourism market [46] and the nascent technology [16], the turnout remains acceptable for qualitative research purpose, and justifies the inclusion of the results thereafter. Three respondents admitted to a poor understanding of the technology, against one who claimed to have a good one. Regarding the upgrading potential of business models, the answers were equally split between process automation, enhanced transparency, and improved trust. Regarding the (open-ended) question of the impact of DLT on existing and new business intermediaries in RM, a single respondent stated that some tourism agencies would be compelled to adjust their portfolio of products and tourism services in the future. No respondent stated that their employer currently had a budget for DLT. One stated that it will be the case in the future, and another did not know. To the (open-ended) question of the impact on the level of disintermediation entailed by this technology, one stated a lack of technical knowledge while another thought that disintermediation carried some opportunities. Regarding the potential on medical tourism, the object of the next section, one respondent identified good potential, one believed the contrary, and the two others either did not know, or did not answer. To the question of the potential of blockchain tokens in order to improve the attractiveness of the tourism industry in RM, three did not know what blockchain tokens referred to, and one respondent believed that they could be used as a customized strategic promotion tool for the industry. To the ultimate open-ended question of the main obstacles to technology adoption one respondent stated that
DLT implementation is the by-product of a proactive mindset; (s)he mentioned the small size of the market, and lack of knowledge about the technology and its advantages.

\section{Medical tourism in Moldova: Can DLTs help?}

We now deliberately focus on a non-financial use case. Our selected destination is an audacious bet, voted the least visited country in Europe in 2013 [47]. RM is a rather unknown country with an embryonic tourism sector that could draw on the success of other developing countries, which have succeeded in improving their attractiveness levels, enhancing the welfare of local population [46].

Within four years, Lonely Planet's outlook drastically improved. RM was placed on the hotlist of the best destinations in Europe: 'Europe's final frontier: little visited, lost in time and always surprising'. It warns 'experienced travelers to Europe', likely to be 'amazed and disoriented by Moldova' [48].

A landscape of low, rolling hills and a secretive cave monasteries are a few of the gems you'll discover. The capital Chişinău, is wonderfully slow, but the countryside is where you'll feel most at peace. Take a trip to Orhei, an hour's drive north of Chișinău, for a hike through fields and forests and a glimpse at the sacred Orheiul Vechi. [49]

Starting in 4000 B.C., the Sumerians built a place around a thermal spring, visited by travellers for its healing properties. In India, there have been Yoga and Ayurveda healing techniques for 5000 years, attracting thousands of persons looking for health improvement. In Japan, people have travelled for over 1000 years for medical purposes to the 'Onsen' mineral springs. In Greece, pilgrims used to travel to Epiduria, considered the 'Sanctuary of the healing God Asklepios'. Starting in the 16th century, Europe became a destination looked for medical tourism, due to roman baths or spa. Amidst the popularity of worldwide travel, a growing number of people are today aligning their trips with healthcare services. The basis of this movement is known as medical tourism. The medical tourist is someone who travels outside the borders of their country, in order to benefit from medical services. This notion excludes expatriates, medical emergencies, and companions of medical tourists. Medical tourism is a particular form of patient mobility, where patients travel across borders or to overseas destination to receive treatments including fertility, cosmetic, dental, transplantation and elective surgery [50]. The scope of medical tourism is widening due to the customization of consumer expectations [51].

There is no consensus on the size of the global medical tourism market. Research companies provide estimates of the market turnover and growth potential. Allied Market Research [x] stated that the global medical tourism market was valued at $\$ 53.77$ billion in 2017 and is estimated to reach $\$ 143.46$ billion by 2025 , registering a $12.9 \%$ growth rate from 2018 to 2025. Based on research conducted by this organization, it was estimated that around 20 million people 
travel across the world each year for medical tourism purposes, spending an average of $\$ 3410$ per visit [57]. The global medical tourism market was valued at approximately only USD 15.5 billion in 2017, and is expected to generate revenue of around USD 28.0 billion by the end of 2024, growing 8.8\% between 2018 and 2024 [58]. Regardless of these major variations between estimates, we encourage researchers to revise their projections downwards in light of the Coronavirus pandemic [59].

Table 3: Benefits, drivers and consumers expectations Sources: [52] [53] [54] [55] [56]

\begin{tabular}{|c|c|c|}
\hline Benefits & Drivers & Consumer expectations \\
\hline Lower cost & Powerful Market-drivers & Quality (real or perceived) \\
\hline Avoiding queues & Globalization trends & Affordability \\
\hline New treatments become available & Strength of the demand-side & Availability \\
\hline Some treatments are illegal at home & Empowered patient base & Accessibility \\
\hline $\begin{array}{c}\text { Welfare-enhancing sector, source of } \\
\text { comparative advantage for } \\
\text { developing countries }\end{array}$ & ICT revolution & Trust in the staff and clinic \\
\hline Faster adoption of innovation & $\begin{array}{c}\text { Decreasing cost of travel and } \\
\text { transport liberalization }\end{array}$ & Confidentiality \\
\hline
\end{tabular}

In February 2020, the Medical Tourism Association [61] organized a webinar titled 'The Coronavirus \& It's Impact to Medical Tourism', in which Karen Timmons, CEO of Global Healthcare Accreditation, warned against the slowdown of airlines resulting in unprecedented levels of diligence for the risk of travelling. In the context of a pandemic, high-quality accreditation will become a sine qua none for travel agencies offering medical tourism services so as to ensure compliance with WHO guidelines and national health regulatory standards. The impact of the pandemic is likely to be enormous as periods of quarantine before entering some countries might deter medical tourists in the future. In a post-COVID-19 world, countries will undergo massive training efforts by health professionals, and implement procedures related to infection control of travellers. Compliance with health standards will become the new markers of competitiveness. In this respect, small medical facilities will come under closer scrutiny [61]

Medical tourism in RM is a nascent and unstructured industry. We present hereafter the relevant data supplemented by a SWOT analysis, and draw some perspectives. Data in Table 4 was obtained on the website of the National Bureau of Statistics that publishes yearly information on all tourism agencies and tour-operators providing tourism services in RM. Tourist flows are broken down into (1) recreational and leisure purposes, (2) business and professional, and (3) treatment. The website of the statistical Bank (another state institution) provides detailed information about the activity of travel agencies and tour operators, by purpose of visit, from 2000 to 2019.
Table 4: Statistics on medical tourism (2015-2019)

\begin{tabular}{|c|c|c|}
\hline Year & \% of total incoming tourism & Number of medical tourists \\
\hline 2015 & 3.1 & 480 \\
\hline 2016 & 3.9 & 612 \\
\hline 2017 & 4.5 & 788 \\
\hline 2018 & $3 \%$ & 584 \\
\hline 2019 & 2.8 & 550 \\
\hline
\end{tabular}

Table 5: Strengths/Weaknesses/Opportunities/Threats analysis

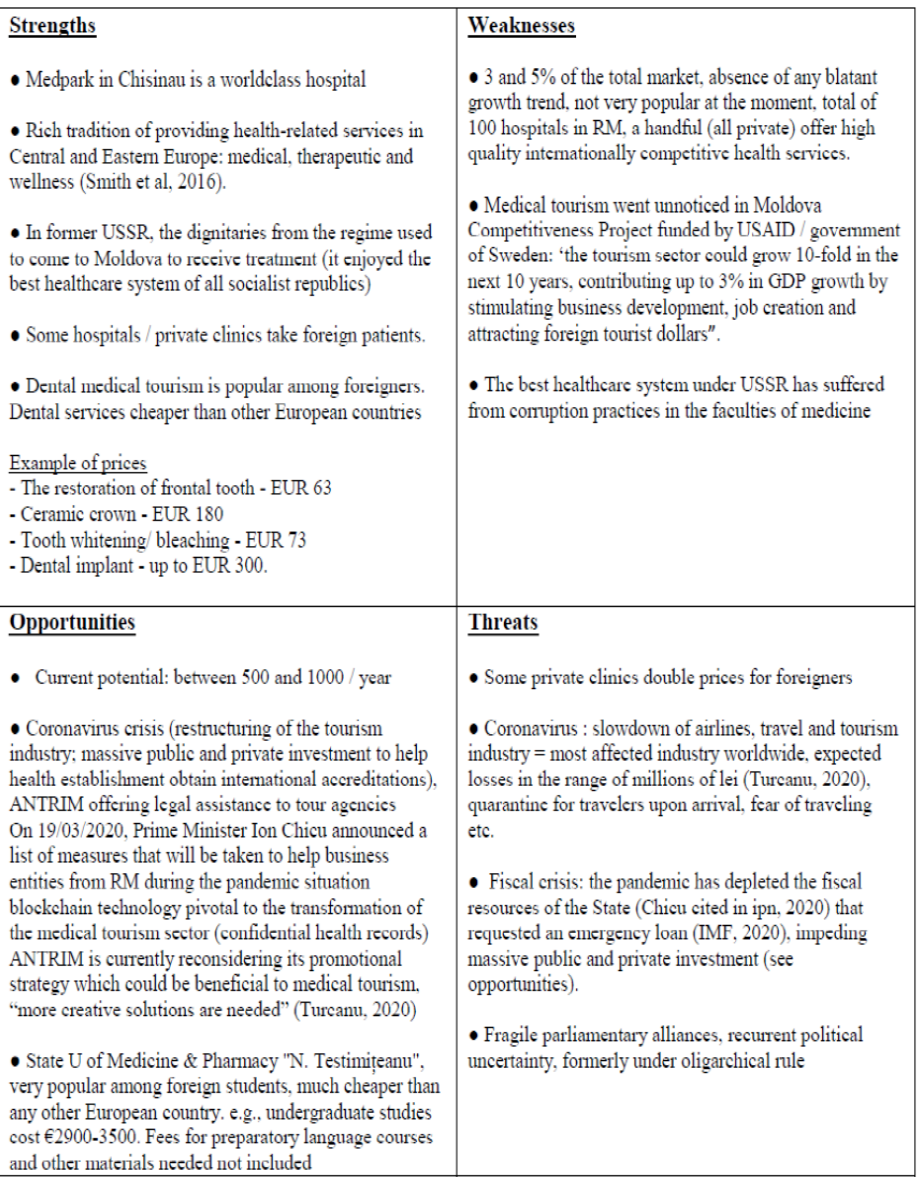

After one year of evaluation and with 1500 indicators tested, Medpark International Hospital, a Chisinau private hospital was the first medical institution to become Joint Commission International accredited in 2014, in RM, and in Eastern Europe with 94 out of 100 points, a near-perfect score [62]. Dr Olga Schiopu Medical Director of Medpark describes the outstanding modern facilities of this cuttingedge establishment that includes four specialized operating theatres (cardiac surgery, neurosurgery, trauma and general surgery) and an in vitro Fertility Centre. There is a high level of medical expertise of doctors who have all undergone postgraduate training in elite universities in Europe or North America. The cardiac centre offers treatment against acute myocardial infarction and cardiac surgery). Other popular 
areas of intervention include hip replacement and ophthalmology.

Medpark International Hospital is a top destination on medical tourism market. This is possible due to advantages such as accessibility in terms of transportation (air, road), highly qualified medical staff, state of the art medical equipment, comprehensive care under one roof, care for the patient, affordable prices and the list could go on [63].

Another asset of RM is the excellent language skills characteristic of an educated workforce. At Medpark, doctors communicate with patients in English, Romanian, Russian, and Turkish. Other languages are made available upon payment of an interpreter's fee [63]. Dr Schiopu recognises that the biggest challenge facing the growth of medical tourism in RM is reassurance about the country, its safety for travel and tourism purposes. In this regard, the initiative of Moldova Tours 2.0 [46] is timely and welcome, as it sets forth to promote tourism and educate people about what RM, once the least visited country in Europe [47], has to offer. With the help of video calls and exchange of information prior to the first visit, the pricing of healthcare services for medical tourism purposes (for complex surgery) could be more accurate and reinforce trust. As explained by the Medical Tourism Quality Alliance [64]:

Patients looking for medical care and treatment abroad need accurate up-to-date reliable information. Whether a website or a medical tourism company can provide the sort of information that will answer concerns about best quality or high standards of patient safety and care management is often a concern. Some patients consider accreditation status and word of mouth recommendations before they make their choice of hospital, it's a definite improvement over relying only on the internet for information or choosing the lowest cost.

\section{DLT solutions and Electronic Health Records (EHR)}

Not all consumption of healthcare services abroad is medical tourism, for instance, the occurrence of emergencies while travelling abroad. Clinicians often find themselves in a critical, if not perilous, situation when lacking any health record on their foreign patient. The delivery of quality healthcare is always at stake, and in some emergency situations, human lives are too [44]. When a person is travelling outside their home country, and is treated for an emergency, a blockchain ledger could help detect a competent expert, who would have access to the healthcare data remotely in case of a rare condition. Due to privacy concerns related to EHRs, patients could store encrypted (therefore confidential) vital information on blockchain-powered Internet-of-Things (IOT) medical devices, and instruct who has access to the private key and the patient's medical information. It could store medical procedures and more advanced directives, such as not-toresuscitate orders [65]. This amounts to patient-centric care (the self-management of healthcare conditions by patients). The stakes are high both for healthcare clinicians and patients: in modern societies, cultures and organized groups, the dissemination of medical data has been perceived to be a breakthrough for the discovery of new techniques and therapies for curing diseases' [66]. How about digitising currency circulating in the health micro-economy? Abid Hospital in Islamabad, Pakistan, was the first Asian hospital to accept the PakCoin cryptocurrency. Technological feat is never an end in itself; this unique experiment had no impact on healthcare quality and medical tourism flows. A more effective application would be to reach out to the unbanked population [67]. In a post-COVID-19 world wherein pockets of poverty are expected to worsen, the reinvention of tourism shall involve this massive segment of the world population. Blockchain tokens prove useful by helping store and securely transfer patient-related and legal information. Usually, the healthcare provider, not the patient, retains access to past data. The siloed nature of healthcare data scattered across various healthcare organisations poses the issue of interoperability between different healthcare providers. Of course, issues of fragmentation and lack of cohesiveness of health records are not limited to medical tourism in developing countries, as they also pertain to large and developed countries such as the USA: 'it's no exaggeration to say that our EHR systems' lack of interoperability is the single strongest barrier to nationwide population health management' [68]. MedRec is a decentralised EHR management system [69]. EHRs are signed digitally, thereby ensuring the existence of an unaltered copy. It is the signature, not the record itself, which is stored on the blockchain ledger. MedRec notifies to the patient the read and write permissions over the EHR. A cryptographic hash of the record protects against tampering, thereby guaranteeing data integrity to all network participants. The block content is made of healthcare data ownership and viewership permissions, while the healthcare community forms the thrust of P2P network. The objective of MedRec is to develop a userfriendly interface that simplifies direct interaction between patients and EHRs that span over different healthcare providers. The next step will be to increase the complexity level of the interface by introducing a richer dataset comprising more data types, contributors and users. DLT, through a decentralized control mechanism, allows the healthcare system to do away with another layer of middlemen, and enhances the control of the patient over medical data. Furthermore, healthcare blockchain ledgers become time-stamped, auditable and programmable with the help of Ethereum-based smart contracts that help automate and track state transitions (e.g. change in viewership rights and entry of a new record in the system).

Digital identity, paramount in healthcare management can be tackled today by DLT [70], is enhanced by the association of widely accepted forms of identity with public key cryptography [71]. After referring a blockchain to confirm permissions via the database authentication server, a syncing algorithm handles 'off-chain' data exchange between a patient database and a provider database [72]. The use of multiparty off-chain channels solves the scalability problem of the Ethereum blockchain and, by extension, other blockchains [71]. Given the size of EHR, this breakthrough proves useful for the incentivisation and enforcement of smart contracts between actors of the healthcare system across institutions and countries. The adoption of DLT could help promote decentralized medical travel solutions, and improve HER 
management. Health connected objects could foster smart medical devices. For instance, a surgical device linked to a blockchain through a smart contract could trigger preventive maintenance. IoT-enabled temperature loggers would transmit the temperature parameters of drugs to a blockchain during shipment, while a smart contract monitors its stability. DLT could help create tamperproof certificates of medical necessity in a trustless environment, thereby stipulating which healthcare services are necessary for the patient by a certified clinician. IoT devices and blockchain smart contracts can become tools facilitating diagnosis [73] when connected to a machine-learning algorithm (e.g. glucose levels and diabetes). DLT-powered EHR are well adapted to cloud-based environments, which have attracted substantial interest from patients, health institutions and researchers alike [74].

\section{Concluding remarks}

We have shed light on the ongoing debate in DLT research of an existential symbiotic relationship between the token and the network [6]. We have provided a counter-intuitive and evidence-based view by arguing that promising tourism use cases lie outside the monetary and financial sphere. The expansion of the DLT space has paved the way for a wide range of non-monetary use cases displaying looser relation strength. A multitude of use cases with a weak relation draw on the capability to securely store and transfer information/data. In Table 1, successful projects display weak or loose token/network relation strength. After conducting a correlation test, the null hypothesis ( $\mathrm{rs}=0$, no correlation between relation strength and success indicator) is not rejected (Figure 7). These preliminary results warrant caution as correlation and/or lack thereof do not imply causation. Room exists for future successful monetary use cases in the tourism sector, although we wish to warn against media hype.

In medical tourism, lower medical costs, international accreditations, competent and multilingual doctors are the building blocks of enhanced attractiveness. In the French philosophical tradition of Althusser [75], the infrastructure, namely the economic base, is the foundational layer of the social system while the superstructure (i.e. the upper layers) is both the essence of the visible structure and the ideological governance of the infrastructure. Along these lines, the evolution of the infrastructure determines that of the superstructure. Arguably, Nakamoto [76] favours the opposite stance with his groundbreaking analysis of decentralisation. In the case at hand, the infrastructure, namely healthcare facilities and professionals, is determined by the superstructure, namely organisational protocols and technological projects. We note that the superstructure of RM still lacks a decentralised technological layer pivotal in creating an environment of trust and transparency; hence, our rationale for blockchain technology.

Finally, let us mention the 2020 coronavirus pandemic:

At this moment we are realistic: now is not the right time to travel to and from many places. All travelers should follow government advice and as a further measure consider if their journey is responsible and essential in the current context [77].
Vicol and Mogîldea [78] explain that an EU-wide recession will reduce exports and remittances, and put pressure on the national currency. Yet, 'the tourism sector, like no other economic activity with social impact, is based on interaction amongst people' [79]. RM would hence benefit from an organizational platform channelling the forces capable of combining DLT, big data analytics, cloud storage and IoT medical devices in a creative fashion, thereby conducive to welfare-enhancing innovation based on data-sharing, higher accessibility and an attractive medical tourism sector.

Competing interests:
Founder and Owner of Moldova Tours 2.0 (cited in the paper)

Ethical approval:

Not applicable.

Author's contribution:

I have conducted the totality of the research

\section{Funding:}

None declared.

\section{Acknowledgements:}

Thank you to the respondents of the online blockchain survey in Moldova, MedPark Hospital for sending me updated information (for the COVID-19 crisis) and the JBBA reviewers for helping me improve this manuscript.

\section{References}

[1] A. I. Ozdemir, I. M. Ar and I. Erol, "Assessment of Blockchain Applications in Travel and Tourism Industry", Quality \& Quantity, pp. 1-15, 2019.

[2] I. Önder and U. Gunter, "Blockchain: Is it the Future for the Tourism and Hospitality Industry?", Tourism Economics, 2020, September. Available: 10.1177/1354816620961707.

[3] E. Colombo and R. Baggio, "Tourism Distribution Channels: Knowledge Requirements", in Knowledge Transfer to and within Tourism: Academic, Industry and Government Bridges, N. Scott, M. De Martino and M. Van Niekerk, Ed. Bingley, UK: Emerald, 2017, pp. 289-301.

[4] A. Wright and P. De Filippi, "Decentralized Blockchain Technology and the Rise of Lex Cryptographia”, 2015. Available at SSRN: https://ssrn.com/abstract $=2580664$.

[5] R. Solow, "Building a Science of Economics for the Real World", House Committee on Science and Technology, July 20, 2010.

[6] T. Swanson, "Consensus-as-a-Service: A Brief Report on the Emergence of Permissioned, Distributed Ledger Systems". Working Paper, 6 April, p. 8, 2015. Available: http://www.ofnumbers.com/wpcontent/uploads/2015/04/Permissioneddistributedledgers.

[7] M. Pilkington, "Blockchain Technology: Principles and Applications", in Handbook of Research on Digital Transformations, Chapter 11, F. Xavier Olleros and 
Majlinda Zhegu. Cheltenham: Edward Elgar, 2016, p. 228.

[8] P. Tasca and C. J. Tessone, "A Taxonomy of Blockchain Technologies: Principles of Identification and Classification”, Ledger, vol. 4, 2019.

[9] G. F. Jenks, "The Data Model Concept in Statistical Mapping", International Yearbook of Cartography, vol. 7, pp. 186-190, 1967.

[10] M. Chan, S. Kemp and J. Finsterwalder, "The Concept of Near Money in Loyalty Programmes", Journal of Retailing and Consumer Services, vol. 31, pp. 246-255, 2016.

[11] C. Ziotis, P. Tugwell and N. Chrysoloras, "Greece Imposes Capital Controls as Fears of Grexit Grow", Bloomberg, 29 June, 2015. Available:

https://www.bloomberg.com/news/articles/2015-0629/greece-imposes-capital-controls-banks-close-tocontain-fallout-ibh78tb7.

[12] B. Kelly, "Greek Island Agrees to Test Digital Currency", CNBC, 8 July, 2015. Available: https://www.cnbc.com/2015/07/08/greek-islandagrees-to-test-digital-currency-commentary.html.

[13] Bitcoincryptocurrency.com, "CNE Drachmae Market: Moldova's Cryptocurrency Exchange?”, 2020.

Available: https://bitcoincryptocurrency.com/cnedrachmae-market/.

[14] N. Miller, "Is Nautiluscoin a Scam?”, 11 July, 2015. Available: https://www.ccn.com/is-nautiluscoin-ascam/.

[15] Antonopoulos, “Tweet”, 29 June, 2015. Available: https://twitter.com/aantonop/status/6155715066309 05856.

[16] M. Pilkington, R. Crudu and L. G. Grant, "Can DLT and Bitcoin Lift a Country Out of Poverty? The Example of the Republic of Moldova", International Journal of Internet Technology and Secured Transactions, 2017.

[17] D. Kowalewski, J. McLaughlin and A. Hill, "Blockchain Will Transform Customer Loyalty Programs", Harvard Business Review, March 14, 2017.

[18] S. Crnojevi and I. Katzela, "Chain of Points: Transforming Loyalty into Rewards", White Paper, 2017. Available: https://chainofpoints.com/cop_ whitepaper.pdf.

[19] S. Anderson, "Nearly Four Billion Customers in Loyalty Programs", Payment Week, 5 March, 2017. Available: https://paymentweek.com/2017-7-5nearly-four-billion-customers-loyalty-programs/.

[20] M. Fare and P. O. Ahmed, "Why Are Complementary Currency Systems Difficult to Grasp within Conventional Economics? Revue Interventions économiques", Papers in Political Economy, vol. 59, 2018.

[21] M. Pilkington, "The Emerging ICO Landscape - Some Financial and Regulatory Standpoints", February 8, 2018. Available at SSRN: https://ssrn.com/ abstract $=3120307$.

[22] K. Helms, "Bitcoin Adoption in Thailand Led by Tourism Industry”, Bitcoin.com, 18 April, 2017. Available: https://news.bitcoin.com/bitcoinadoption-thailand-tourism-industry-scaling-debate/.

[23] A. Costello, "Travel Sites that Accept Cryptocurrencies”, blogpost, 23 November, 2019.
Available: https://medium.com/hashmartblog/travel-sites-that-accept-cryptocurrenciesd1 ad55c6bd0a.

[24] L. Tassev, "These Tourist Destinations Welcome Bitcoin Cash Enthusiasts", Bitcoin.com, 25 May, 2019. Available: https://news.bitcoin.com/these-touristdestinations-welcome-bitcoin-cash-enthusiasts/ ?omhide $=$ true.

[25] Deloitte, "Blockchain: An Introduction and UseCases", 12 June, 2018. Available: https:// www2.deloitte.com/content/dam/Deloitte/be/Docu ments / finance/BE-Blockchain $\% 20$ for $\% 20$ the $\%$ 20 financial $\% 20$ industry.pdf.

[26] J. Simmons, "Thailand's Largest Bank Works on Ripple Based App for Tourists", 27 March, 2020. Available: https://www.crypto-news-flash.com/ thailands-largest-bank-works-on-ripple-based-app-fortourists/.

[27] M. Swan, Blockchain: Blueprint for a New Economy. Cambridge, MA: O'Reilly Media, 2015.

[28] Axa, "Fizzy, Smart Insurance. Automatic Compensation", 13 September, 2017. Available: https://www.youtube.com/watch?v=xJZulZ_-CMI.

[29] J. Raynal, "Clap de fin pour Fizzy, l'application phare d'Axa dans la Blockchain", 8 November, 2019. Available: https://www.latribune.fr/entreprisesfinance/banques-finance/assurance/clap-de-fin-pourfizzy-l-application-phare-d-axa-dans-la-blockchain832676.html.

[30] M. Bassig, "Hoteliers and Tourism Business Owners: Travel, Tourism, and Hotel Review Sites You Should Monitor?", Review Trackers, 13 November, 2012. Available: https://www.reviewtrackers.com/hotelierstourism-business-owners-travel-tourism-hotel-reviewsites-monitor/.

[32] R. Weston, H. Hamele, M. Balas, R. Denman, A. Pezzano, G. Sillence, K. Reiner, A. Grebenar and M. Lawler, "Research for TRAN Committee - European Tourism Labelling, European Parliament", Policy Department for Structural and Cohesion Policies, Brussels, 2018. Available: https://www.europarl. europa.eu/RegData/etudes/STUD/2018/617461/IP OL_STU(2018)617461_EN.pdf.

[33] Finyear, "Buuyers: la blockchain garantit la fiabilité des avis clients", 21 July, 2016. Available:

http://www.finyear.com/Buuyers-la-blockchaingarantit-la-fiabilite-des-avis-clients_a36787.html.

[34] Microsoft, "Webjet and Microsoft Build First-of-aKind Travel Industry Blockchain Solution",

November 8, 2016. Available: https://news.microsoft. com/en-au/2016/11/08/webjet-and-microsoft-buildfirst-of-a-kind-travel-industry-blockchainsolution/\#_ftn1.

[35] Microsoft, "Webjet Uses Blockchain to Simplify Transaction Disputes in the Travel Industry", 30 March, 2018. Available: https:// customers.microsoft. $\mathrm{com} / \mathrm{fr}$-fr/story/webjet.

[36] Webjet, "News Release, Webjet Launches Rezchain, New Blockchain Technology Enables Error Free Hotel Bookings", 7 November, 2019. Available: https://webbedsuploadstorage.blob.core.windows.net/ uploads/2019/10/Rezchain-WTM-Launch-Release.pdf. 
[37] L. Lu, C. G. Chi and Y. Liu, "Authenticity, Involvement, and Image: Evaluating Tourist Experiences at Historic Districts", Tourism Management, vol. 50, pp. 85-96, 2015.

[38] F. A. Salamone, "Authenticity in Tourism: The San Angel Inns", Annals of Tourism Research, vol. 24, pp. 305-321, 1997.

[39] L. Coleman, "Ethereum-Based Swiss Blockchain Startup Readies Tech for the Food Supply Chain", cryptocoinnews.com, 26 April, 2017. Available: https://www.cryptocoinsnews.com/ethereumfoodblockchainxyz-supply-chain/.

[40] P. Rizzo, "An Asia-Pacific Blockchain Consortium is Forming around Food Supply Chain", CoinDesk, May 22, 2017. Available: http://www.coindesk.com/pwcteams-up-with-alibaba-for-food-supply-blockchaintest/.

[41] Amadeus IT Group, "Blockchain for Travel”, 18 October, 2017. https://www.youtube.com/watch?v= YpS0zoJ9wCU\&feature $=$ emb_logo.

[42] R. Patrício, A. C. Moreira and F. Zurlo, "Gamification Approaches to the Early Stage of Innovation", Creativity \& Innovation Management, vol. 27, no. 4, pp. 499-511, 2018. Available:

https://doi.org/10.1111/caim.12284.

[43] J. Swacha, "Architecture of a Dispersed Gamification System for Tourist Tractions", Information, vol. 10, no. 1, p. 33, 2019.

[44] M. Scott, "The Blockchain and Global Health", Nasdaq.com, 9 May, 2017. Available: http://www.nasdaq.com/article/the-blockchain-andglobal-health-cm786796\#ixzz4jgi3NSUN.

[45] Zawya, "Sihatech Listed Amongst the World's Top 10 Startups", Press Release, 13 November, 2019.

Available: https://www.zawya.com/mena/en/pressreleases/story/Sihatech_listed_amongst_the_worlds_t op_10_startups-ZAWYA20191113082106/.

[46] M. Pilkington, "Tourism for Development in the Republic of Moldova: Empowering Individuals and Extending the Reach of Globalization though an Innovative 2.0 Digital Platform", in Handbook of Research on Individualism and Identity in the Globalized Digital Age, Francis Sigmund Topor, Ed. Japan: Keio University. IGI Global E-Editorial Discovery, 2016, pp. 500-531.

[47] Pettersen, "Moldova: Embracing Its Status as Europe's Least-Visited Country", Lonely Planet, 2 July, 2013. Available:

https://www.lonelyplanet.com/articles/moldovaembracing-its-status-as-europes-least-visited-country.

[48] Lonely Planet, "Best in Europe, Our Hotlist of European Destinations", 2017. Available: https://www.lonelyplanet.com/best-in-europe.

[49] J. Bishop, "The 10 Best Places to Visit in Europe in 2017”, 23 May, 2017. Available:

https://www.forbes.com/sites/bishopjordan/2017/0 5/23/best-places-to-visit-in-europe/\#50ba7a133bdc.

[50] N. Lunt, D. Horsfall and J. Hanefeld, "Medical Tourism: A Snapshot of Evidence on Treatment Abroad", Maturitas, vol. 88, pp. 37-44, 2016.

[51] I. G. Cohen and E. Prall, "Medical Tourism", in The Wiley Blackwell Encyclopedia of Consumption and
Consumer Studies, T. Cook and J. M. Ryan Ed. Chichester: WileyBlackwell, 2015, p. 168. Available: 10.1002/9781118989463.wbeccs168.

[52] V. Runnels and P. M. Carrera, "Why Do Patients Engage in Medical Tourism?", Maturitas, vol. 73, no. 4, pp. 300-304, 2012.

[53] J. Y. Han, E. M. Choi and K. Y. Ji, "An Analysis of the Importance-Satisfaction of Convergent Medical Tourism Service Quality", Journal of Digital Convergence, vol. 13, no. 7, pp. 403-412, 2015.

[54] J. Connell, "Contemporary Medical Tourism: Conceptualisation, Culture and Commodification", Tourism Management, vol. 34, pp. 1-13, 2013.

[55] C. L. Andrei, G. Tigu, R. M. Dragoescu and C. J. Sinescu, "Analysis of Medical Tourism for Cardiovascular Diseases", Amfiteatru Economic Journal, vol. 16, no. 8, pp. 1136-1150, 2014.

[56] A. Lubowiecki-Vikuk and D. Dryglas, "Medical Tourism Services and Medical Tourism Destinations in Central and Eastern Europe-the Opinion of Britons and Germans", Economic Research-Ekonomska istraživanja, vol. 32, no. 1, pp. 1256-1274, 2019.

[57] Allied Market Research, "Medical Tourism Market by Treatment Type (Dental Treatment, Cosmetic Treatment, Cardiovascular Treatment, Orthopedic Treatment, Neurological Treatment, Cancer Treatment, Fertility Treatment, and Others): Global Opportunity Analysis and Industry Forecast, 20182025”, January, 2019. Available: https:/ /www. alliedmarketresearch.com/medical-tourism-market.

[58] Edelheit, "State of the Medical Tourism Industry", 2020. Available: https://www.magazine. medicaltourism.com/article/state-of-the-medicaltourism-industry.

[59] Zion Market Research, "Medical Tourism Market by Treatment Type (Cancer Treatment, Orthopedic Treatment, Fertility Treatment, Cardiovascular Treatment, Neurological Treatment, and Others): Global Industry Perspective, Comprehensive Analysis and Forecast, 2017-2024", Press Release, 22-June, 2018. Available: https://www.zionmarket research.com/report/medical-tourism-market

[60] Express Healthcare, "COVID-19 Proving Fatal for Medical Tourism Industry”, 1 April, 2020. Available: https:/ /www.expresshealthcare.in/covid19updates/covid-19-proving-fatal-for-medical-tourismindustry $/ 418100 /$.

[61] Medical Tourism Association, "The Coronavirus \& It's Impact to Medical Tourism", Youtube video, 13 February, 2020. Available: https://www.youtube. com $/$ watch?time_continue $=1670 \& v=6$ FujaIpHz5Q\& feature=emb_logo.

[62] G. Pramod, "Medpark Is the First and Only JCI Accredited Medical Facility in Moldova", 15 August, 2014. Available: https://www.placidway.com/article/ 1453/Medpark-Is-the-First-and-Only-JCI-AccreditedMedical-Facility-in-Moldova.

[63] PlacidWay, "Interview with Dr. Olga Schiopu Medical Director of Medpark International Hospital", 11 December, 2013. Available: https://www. placidway.com/article/1347/Interview-with-Dr-OlgaSchiopu-Medical-Director-of-Medpark-Moldova. 
[64] Medical Tourism Quality Alliance, "Getting the Best Care and Best Value in Medical Tourism”, 2020. Available: https://mtqua.org/medical-tourism-quality.

[65] C. M. Angst and R. Agarwal, "Adoption of Electronic Health Records in the Presence of Privacy Concerns: The Elaboration Likelihood Model and Individual Persuasion", MIS Quarterly, vol. 33, no. 2, pp. 339370, 2009.

[66] Q. Xia, E. B. Sifah, K. O. Asamoah, J. Gao, X. Du and M. Guizani, "MeDShare: Trust-Less Medical Data Sharing among Cloud Service Providers via Blockchain", IEEE Access, vol. 5, pp. 14757-14767, 2017. Available: 10.1109/ACCESS.2017.2730843.

[67] A. Zubair, "Abid Hospital in Pakistan becomes the First Asian Hospital to Accept Cryptocurrency", Pakwired, 10 March, 2017. Available: https://pakwired.com/abid-hospital-becomes-firstasian-hospital-to-accept-cryptocurrency/.

[68] G. D'Arcy Guerin, "Could DLT Be the Answer to Health IT Interoperability?”, HIT Consultant, 23 March, 2017. Available: http:/ hitconsultant.net/2017/03/23/blockchaintechnology-healthcare-it-interoperability/.

[69] A. A. Ekblaw, J. Halamka and A. Lippman, "A Case Study for Blockchain in Healthcare: "MedRec" Prototype for Electronic Health Records and Medical Research Data", 2016.

[70] G. Wolfond, “A Blockchain Ecosystem for Digital Identity: Improving Service Delivery in Canada's Public and Private Sectors", Technology Innovation Management Review, vol. 7, no. 10, 2017.

[71] V. Buterin and J. Poon, "Plasma: Scalable Autonomous Smart Contracts", White Paper, 2017. Available: http://plasma.io/plasma.pdf.

[72] A. Khatoon, "A Blockchain-Based Smart Contract System for Healthcare Management", Electronics, vol. 9, no. 1, p. 94, 2020.

[73] R. Krishnamurthy, "The Voyage of Discovery: Blockchain for Pharmaceuticals and Medical Devices", Beyond Standards is brought to you by the IEEE Standards Association, 17 April, 2017. Available: https://beyondstandards.ieee.org/generalnews/voyage-discovery-blockchain-pharmaceuticalsmedical-devices/.

[74] M. R. M. Assis, L. F. Bittencourt and R. TolosanaCalasanz, "Cloud Federation: Characterisation and Conceptual Model", Proceedings of the 2014 IEEE/ACM 7th International Conference on Utility Cloud Computing (UCC), pp. 585-590, December, 2014.

[75] L. Althusser, Idéologie et appareils idéologiques d'État (pp. 263-306). Presses Universitaires de France, 2011.

[76] S. Nakamoto, "Bitcoin: A Peer-to-Peer Electronic Cash System", 2008.

[77] Lonely Planet, “Ask Tom: Lonely Planet Expert Answers Your Pressing Travel Questions in Light of the Coronavirus Pandemic", Tom Hall, 12 March, 2020. Available: https://www.lonelyplanet.com/ articles/expert-travel-advice-coronavirus-covid-19.

[78] D. Vicol and M. Mogîldea, "Economic Impact of COVID-19: What Can We Expect in the Case of Moldova? Op-Ed", ipn, 21 March, 2020. Available: https://www.ipn.md/en/economic-impact-of-covid19-what-can-we-expect-in-7978_1072344.html.

[79] UNWTO, "COVID-19, Putting People First", 2020. Available: https://www.unwto.org/tourismcovid-19.

\section{Notes}

$0 \leq \mathrm{r} \leq 1$

https://www.reddit.com/r/Bitcoin/comments/8c8hc7/destinia_claim_they_accept_bitcoin_for_flights iii https://www.forbes.com/sites/lukefitzpatrick/2019/04/25/cheapair-to-accept-ethereumpayments/\#d20deb7515dd

https://www.phocuswire.com/Bitcoin-travel-companies

https://www.ch-aviation.com/portal/news/84297-taiwans-far-eastern-air-transport-ceases-operation "https://www.reddit.com/r/btc/comments/451il3/my_experience_with_abitsky/

https://www.bitcoin-accepted.com/bitcoin-now-accepted-norwegian-air/

viii https://map.bitcoin.com/

ix https://www.thecryptoassociate.com/ripplenet-usage-surges-300-in-2020-q1/

https://www.latribune.fr/entreprises-finance/banques-finance/assurance/clap-de-fin-pour-fizzy-1application-phare-d-axa-dans-la-blockchain-832676.html

\&i http://entreprises.lefigaro.fr/buuvers-75/entreprise-792584872

ii https://www webbeds.com/webjet-limited-unveils-rezchain-at-wtm/

siii https://www phocuswire.com/Technology-travel-experience

viv https://www.zawya.com/mena/en/press-

releases/story/Sihatech_listed_amongst_the_worlds_top_10_startups-ZAWYA20191113082106/

${ }_{x v}$ A proper application of the Jenks optimisation method would require the minimisation of the squared A proper application or the Jenk deviations of each class means according a a prespecifed algorithm. Howeve, our fixed choice of refinement of this statistical treatment for future research as the number of tourism use cases and statistical observations expand.

xvi The results of the questionnaire are available in Romanian here https://docs.google.com/

forms/d/1tQt9OVquhBrMTz3aCttw9yNZT5ryIEvPeIRkdN6QawI/edit\#responses 